\title{
Real-World Evidence: Pharmacoepidemiology for Daily Clinical Practice-An Experience from Colombia
}

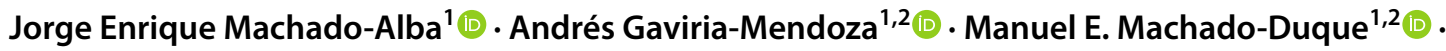 \\ Luis Fernando Valladales-Restrepo ${ }^{1,2}$ (1)
}

Published online: 4 August 2020

(c) The Author(s) 2020

\section{Introduction}

In recent years, the use of real-world data (RWD) has rapidly increased in many fields of healthcare delivery and research [1]. These data, when properly used, may be translated into real-world evidence (RWE) intended to help practitioners and decision makers improve clinical practice $[2,3]$. The aim of the current commentary was to describe the experience of using RWD and RWE by a research group in Colombia in the field of pharmacoepidemiology and pharmacovigilance (Grupo de investigación en Farmacoepidemiología y Farmacovigilancia, from Universidad Tecnológica de Pereira - Audifarma S. A, Pereira, Colombia), and to describe examples with impacts on clinical practice.

\section{Real-World Data and Real-World Evidence}

According to the US Food and Drug Administration (FDA), RWD comprises "data relating to patient health status and/or the delivery of health care routinely collected from a variety of sources" $[2,3]$. This definition implies that RWD can be readily accessed from many systematized databases that are usually intended for administrative purposes-for example, those related to drug claims - and thus have great potential in the field of pharmacoepidemiology and pharmacovigilance. These data are especially useful for conducting retrospective observational studies that may ultimately impact

Jorge Enrique Machado-Alba

machado@utp.edu.co

1 Grupo de Investigación en Farmacoepidemiología y Farmacovigilancia, Universidad Tecnológica de Pereira-Audifarma S. A., Calle 105 No. 14-140, Pereira, Risaralda 660003, Colombia

2 Grupo Biomedicina. Facultad de Medicina, Fundación Universitaria Autónoma de las Américas, Pereira, Colombia on clinical practice, with the advantage of requiring few economic resources (compared to traditional experimental designs and without sacrificing a rigorous methodology and scientific method) [4].

Despite the inherent limitations of observational studies, the results of these data can serve as RWE, which is defined as "the clinical evidence regarding the usage, and potential benefits or risks of a medical product derived from analysis of RWD" [2, 3]. For example, in the UK, clinical practice guidelines increasingly include references to studies based on observational data as support for traditional randomized controlled trials [5]. Additionally, it has been estimated that $15 \%$ of the randomized controlled trials published in highimpact journals during 2017 could have been conducted by using RWD instead [6].

The advantage of RWE is that it is gathered in actual clinical and day-to-day practice and that its findings are expected to more reliably reflect the effectiveness and safety of drugs, and to serve as a basis for new interventions and further research [7]. Despite the aforementioned worldwide increased usage and application of RWD and RWE, in the South American context this information has generally only been utilized in academic research and pharmacovigilance [1]. For example, drug utilization research in Latin American countries has limitations due to fragmented healthcare systems, the lack of nationwide databases, or the poor knowledge of decision makers regarding these kinds of studies [8]. However, RWE usage could have an impact on the healthcare of the population in daily clinical practice as its visibility and practicality in the region increases.

\section{Research Group Experience}

The Colombian health system covers the entire population (approximately 50 million people). This system is basically organized into two plans: contributory (paid jointly 
by workers and their employers) and subsidized (paid by the state), both of which are managed by insurance companies that are responsible for all patient healthcare. Our research group works in the field of pharmacoepidemiology and pharmacovigilance, and we use RWD primarily from a database with drug-dispensing claims of the contributory plan. This database is managed by Audifarma S.A. (the largest drug-dispensing company in the country) and contains information that recently reached a potential representation of approximately 8 million people. The group's experience with the pharmacoepidemiological characterization of the Colombian population has been interesting, as it allows not only the description of but also intervention in certain situations.

Access to data from drug dispensaries, which combines diagnostic codes and electronic health records, has enabled the analysis of acute and chronic health-related conditions. Thus, it has been possible to revise health prescription alerts (such as for the risk of metoclopramide in children and, at high doses, in adults) and to conduct several interventions, including those related to educational material and meetings, with the prescribing physicians and medical directors [9]. For example, from more than 1500 patients using oral ketoconazole for $>15$ days (risk of fatal liver injury), $30 \%$ stopped the medication after the interventions [9].

In another project, the prescription profile of antibiotics in skin infections in a primary-care hospital aided in identifying potentially inappropriate use of these medications in $25 \%$ of patients (especially regarding molecule selection according to the severity of the disease or purulence) [10]. This work was cited in the most recent Colombian clinical practice guidelines for the diagnosis and management of skin and soft tissue infections [11].

Regarding chronic conditions, cardiovascular diseases are of foremost importance. In this respect, pharmacoepidemiologic analysis with RWD has been of great utility in our context. For example, a group of over 7000 patients was identified using conventional-release verapamil for the treatment of hypertension, which exposed them to serious adverse effects or even increased mortality. Of these patients, 1922 (26.3\%) received prescription changes to improve their safety after the interventions, with the treating physicians following the instructions of insurance companies after the results were communicated to them by the research group [12].

On the same topic, the concomitant use of $\beta$-blockers with non-dihydropyridine calcium channel blockers was assessed in people older than 65 years; from a database of approximately 6.5 million patients, more than 500 patients with this risk of drug-drug interaction were identified [13]. With this information, the insurance company responsible for their healthcare was able to modify the therapy in $44 \%$ of the patients, thereby helping physicians comply with the recommendations for the appropriate use of this group of drugs [13].

Other studies aimed to improve the prescription of medications that are used commonly but may be incorrectly selected, such as losartan at high doses [14], or furosemide as monotherapy in patients with hypertension [15]. In the losartan study, nearly $13 \%$ of patients using this drug for the treatment of hypertension were receiving doses $>100 \mathrm{mg} /$ day (no benefit added). Then, after intervention with prescribers and decision makers, $25.4 \%(n=1832)$ of patients taking high doses were adjusted [14]. In the case of furosemide, we identified 160 patients aged 65 years or older who were using this medication as monotherapy for hypertension treatment, and $42 \%$ of them received an adjustment in their therapy after educational intervention with the prescribers [15].

Finally, some other projects have looked for potential prescribing omissions. For example, in patients older than 65 years with cardiovascular conditions, it was possible to identify an important number of patients who were not prescribed angiotensin-converting enzyme inhibitors despite these patients having heart failure or coronary heart disease (16.5\%), and many of them lacked statins, acetylsalicylic acid, or $\beta$-blockers, which were clearly indicated [16]. In $25.2 \%$ of these cases, adjustments to therapy were made by the healthcare managers of these patients [16].

\section{Conclusion}

The use of RWD and RWE is well established within the field due to their advantages, along with the fact that most health records are now being generated and stored in electronic media in not only high-income countries but also health systems with limited resources. In the Colombian context and according to the experience of our group, some important steps have been taken to conduct pharmacoepidemiological studies using RWD that have an impact in the clinical field. However, there is still much to be improved. It is important for researchers to be trained in and be able to implement the different recommendations and guidelines that aim to improve the quality of evidence generated through studies using RWD, such as those proposed by the International Society for Pharmacoeconomics and Outcomes Research (ISPOR) and the International Society for Pharmacoepidemiology (ISPE) [17]. The databases used should be strengthened and integrated in order to link multiple types of variables and healthcare outcomes. Finally, it is also essential that decision- and policymakers be familiarized with this type of research in support of their work so that patients might benefit from the best available evidence. 
Acknowledgements We thank Claudia Giraldo, Carlos Fernando Tovar, and Soffy Lopez for their support in the interventions and database management.

Authors Contributions All the authors participated in the conception, preparation, discussion, and final revision of the manuscript.

\section{Declarations}

Funding Not applicable.

Conflict of interest The authors have no additional interests to declare.

Availability of data and material Not applicable.

Code availability Not applicable.

Open Access This article is licensed under a Creative Commons Attribution-NonCommercial 4.0 International License, which permits any non-commercial use, sharing, adaptation, distribution and reproduction in any medium or format, as long as you give appropriate credit to the original author(s) and the source, provide a link to the Creative Commons licence, and indicate if changes were made. The images or other third party material in this article are included in the article's Creative Commons licence, unless indicated otherwise in a credit line to the material. If material is not included in the article's Creative Commons licence and your intended use is not permitted by statutory regulation or exceeds the permitted use, you will need to obtain permission directly from the copyright holder. To view a copy of this licence, visit http://creativecommons.org/licenses/by-nc/4.0/.

\section{References}

1. Justo N, Espinoza MA, Ratto B, et al. Real-world evidence in healthcare decision making: global trends and case studies from Latin America. Value Health. 2019;22(6):739-49.

2. Food and Drug Administration. Use of real-world evidence to support regulatory decision-making for medical devices: guidance for industry and Food and Drug Administration staff; 2017. https:// www.fda.gov/regulatory-information/search-fda-guidance-docum ents/use-real-world-evidence-support-regulatory-decision-makin g-medical-devices. Accessed 2 Dec 2019.

3. Food and Drug Administration. Framework for FDA's Real-world evidence program; 2018. https://www.fda.gov/media/120060/ download. Accessed 4 June 2020.
4. Corrao G, Cantarutti A. Building reliable evidence from realworld data: needs, methods, cautiousness and recommendations. Pulm Pharmacol Ther. 2018;53:61-7.

5. Oyinlola JO, Campbell J, Kousoulis AA. Is real world evidence influencing practice? A systematic review of CPRD research in NICE guidances. BMC Health Serv Res. 2016;16:299.

6. Bartlett VL, Dhruva SS, Shah ND, Ryan P, Ross JS. Feasibility of using real-world data to replicate clinical trial evidence. JAMA Netw Open. 2019;2(10):e1912869.

7. Blonde L, Khunti K, Harris SB, Meizinger C, Skolnik NS. Interpretation and impact of real-world clinical data for the practicing clinician. Adv Ther. 2018;35(11):1763-74.

8. Salas M, Lopes L, Godman B, et al. Challenges facing drug utilization research in the Latin American region. Pharmacoepidemiol Drug Saf. 2020. https://doi.org/10.1002/pds.4989.

9. Machado-Alba JE, Solano V, Torres D, Portilla A, Laverde LA, Machado-Duque ME. Monitoring and impact of the disclosure of five health alerts for drugs in Colombia. Rev Salud Publica (Bogota). 2018;20(1):23-6.

10. Castrillón-Spitia JD, Ocampo-Palacio A, Rivera-Echeverry CI, Londoño-Montes J, Martínez-Betancur S, Machado-Alba JE. Prescripción de antibióticos en infecciones de piel y tejidos blandos en una institución de primer nivel. Ces Med. 2018;32(1):3-13.

11. Valderrama-Beltrán S, Cortés JA, Caro MA, et al. Guía de práctica clínica para el diagnóstico y manejo de las infecciones de piel y tejidos blandos en Colombia. Infectio. 2019;23(4):318-46.

12. Machado-Alba JE, Giraldo-Giraldo C, Machado-Duque ME. Quality of conventional release verapamil prescription in patients with arterial hypertension. Rev Calid Asist. 2015;30(2):72-8.

13. Machado-Alba JE, Giraldo-Giraldo C, Aguirre Novoa A. Results of an intervention to reduce potentially inappropriate prescriptions of beta blockers and calcium channel blockers. Rev Calid Asist. 2016;31(3):134-40.

14. Portilla A, Torres D, Machado-Duque ME, Machado-Alba JE. Intervención para la racionalización del uso de losartán. Rev Colomb Cardiol. 2017;24(1):10-4.

15. Machado-Alba JE, Giraldo-Giraldo C, Urbano-Garzón SF. Prescripciones de diuréticos de asa potencialmente inapropiadas en ancianos. Rev Colomb Cardiol. 2017;24(3):217-22.

16. Murillo-Munoz MM, Gaviria-Mendoza A, Machado-Alba JE. Potential prescribing omissions in patients with cardiovascular disease. Int J Clin Pract. 2019;73(12):e13428.

17. Berger ML, Sox H, Willke RJ, et al. Good practices for real-world data studies of treatment and/or comparative effectiveness: Recommendations from the joint ISPOR-ISPE Special Task Force on real-world evidence in health care decision making. Pharmacoepidemiol Drug Saf. 2017;26(9):1033-9. 